\title{
Educação Musical Auxiliada por Computador: Algumas Considerações e Experiências
}

\author{
Evandro M. Miletto ${ }^{1}$ \\ Leandro L. Costalonga ${ }^{2}$ \\ Luciano V. Flores ${ }^{3}$ \\ Eloi F. Fritsch ${ }^{4}$ \\ Marcelo S. Pimenta ${ }^{5}$ \\ Rosa M. Vicari ${ }^{6}$
}

\begin{abstract}
Resumo. $O$ objetivo deste trabalho é tecer considerações relativas a educação musical auxiliada por computador, salientar tópicos que consideramos necessários para este tipo de prática e algumas características de sistemas que os contemplam. Discute, ainda, como explorar a computação musical como meio de inclusão digital, citando experiências de pesquisas na área.
\end{abstract}

Palavras-chave: Educação Musical Auxiliada por Computador, Computação Musical, Composição Musical, Inclusão Digital.

\begin{abstract}
This paper aims to present some considerations about computer aided musical education, to point out topics which we believe are necessary to such practice and also some characteristics of systems that agree with those topics. It also discusses how to use computer music to promote digital inclusion, by referencing experiences of research in this field.
\end{abstract}

Keywords: Computer Aided Musical Education, Computer Music, Musical Composition, Digital Inclusion.

\section{Introdução}

É nossa convicção que para desenvolver sistemas de educação musical que sejam úteis e usáveis tem-se a necessidade de uma perspectiva não só multidisciplinar mas também interdisciplinar, que estabeleça uma integração sistemática e correspondências explícitas entre uma variedade de teorias, modelos, técnicas e ferramentas de diferentes áreas tais como Computação Musical, Educação Musical, Interação Humano-computador e Inteligência Artificial, entre outras. Nosso trabalho nos últimos anos no LC\&M e no Centro de Música Eletrônica da UFRGS (CME) evidencia um esforço de integração destas áreas e segue a tendência atual de mudança de atitude buscando a inclusão de indivíduos com pouco conhecimento musical na comunidade de música. Acreditamos que qualquer pessoa possa desenvolver sua capacidade de ser de fato criadora de cultura musical e não apenas consumidora de uma cultura que já vem pronta, pois a possibilidade de aprender, criar e experimentar material sonoro é uma oportunidade não só de aprimoramento cultural e lazer mas também de redução da exclusão social.

\footnotetext{
${ }^{1}$ Mestrando PPGC - UFRGS - Bolsista CNPq miletto@inf.ufrgs.br

${ }^{2}$ Mestrando PPGC - UFRGS - 1lcostalonga@inf.ufrgs.br

${ }^{3}$ Prof. Instituto de Informática - UFRGS - MSc em Ciência da Computação-1vf@inf.ufrgs.br

${ }^{4}$ Prof. Instituto de Artes - UFRGS - PhD em Informática - fritsch@inf.ufrgs.br

${ }^{5}$ Prof. Instituto de Informática - UFRGS - PhD em Informática - mpimenta @inf.ufrgs.br

${ }^{6}$ Prof ${ }^{a}$. Instituto de Informática - UFRGS - PhD em Informática - rosa@inf.ufrgs.br

*Integrantes do Grupo de Computação Musical da UFRGS - http://www.musicaeletronica.ufrgs.br
} 
Dentro deste contexto, o objetivo deste trabalho é triplo: a) apresentar conceitos de Educação Musical Auxiliada por Computador, b)esclarecer, sugerir e discutir o uso de software musical (não necessariamente construído para Educação Musical) em atividades educativo-musicais, bem como c) relatar algumas experiências e contribuições de nosso grupo de pesquisa que investigam possibilidades do uso da tecnologia computacional para Educação Musical.

O artigo está estruturado da seguinte maneira: esta Introdução é seguida por considerações sobre a educação musical auxiliada por computador, na seção 2 . A seção 3 apresenta alguns software musicais, suas características e como podem ser usados como apoio nas aulas de música. Exemplos dos trabalhos e métodos desenvolvidos pelo LC\&M/CME, bem como pesquisas em andamento, são apresentados na seção 4 e, por fim, a seção 5 contém os comentários finais.

\section{Pressupostos para o uso do computador na educação musical}

Seja qual for o tipo de software criado para uso em educação musical, é importante que sejam observados pressupostos pedagógicos coerentes com os objetivos educativos do contexto e, principalmente, que o mesmo propicie o desenvolvimento musical da forma mais abrangente possível. De acordo com Krüger (Kruger, 1996), poucos software brasileiros de teoria musical são construídos segundo estudos recentes de desenvolvimento cognitivo e musical; ao contrário, fundamentam-se em métodos tradicionais de apresentação, aplicação de conceitos e avaliação de resultados - o que se reflete em sua estrutura técnica, conteúdo e forma de avaliação (Kruger, 1999).

O referencial teórico para muitas pesquisas curriculares na Educação Musical brasileira (Hentschke, 1996) segue as diretivas do Modelo (T)EC(L)A, de Keith Swanwick (Swanwick, 1979). O mesmo ocorre neste trabalho.

Em Educação Musical, segundo Swanwick, é necessário atentar para a promoção de experiências musicais específicas, de diferentes tipos, possibilitando que os alunos assumam diversos papéis em uma variedade de ambientes musicais (Swanwick, 1979, p.42). Isto pode ser realizado mediante o equilíbrio das atividades musicais proporcionadas aos estudantes. $\mathrm{O}$ autor propõe, para atingir tal objetivo, $\mathrm{O}$ Modelo (T)EC(L)A, que apresenta cinco tipos de atividades musicais, ou parâmetros de experiências musicais, definidos da seguinte forma (Swanwick, 1979 p.43-5):

- (Técnica): aquisição de habilidades - aurais, instrumentais e de escrita musical; refere-se ao controle técnico, execução em grupo, manuseio do som com aparatos eletrônicos ou semelhantes, habilidades de leitura à primeira vista e fluência com notação;

- Execução: de obras musicais em público, que implica em uma audiência, não importando o tamanho ou caráter (formal ou informal);

- Composição: formulação de uma idéia musical; usando variadas formas de invenção musical, até improvisação, agrupando materiais sonoros de uma forma expressiva;

- (Literatura): estudos da "literatura de" e "literatura sobre" música; incluindo não somente o estudo contemporâneo ou histórico da literatura da música em si por meio de partituras e execuções, mas também por meio de criticismo musical, histórico e musicológico; e

- Apreciação: audição de obras musicais; 
Os parênteses nas atividades de Técnica e Literatura são utilizados por Swanwick para caracterizá-las como secundárias ao processo educativo (conhecimento sobre música), uma vez que sua função seria prover suporte à Composição, Execução e Apreciação, consideradas centrais ao desenvolvimento musical dos estudantes (envolvimento direto com a música).

Assim, embasados em um modelo teórico de educação musical, a atividade de desenvolvimento de software educacional para a música abrange estratégias peculiares para definição do conteúdo, a partir da identificação do público-alvo da aplicação e do currículo de ensino adequado a este usuário, principalmente em termos do conhecimento formal musical que ele possui, e também na forma de apresentação do conteúdo, levando em conta teorias de ensino/aprendizagem reconhecidas da Educação Musical e da Psicologia Cognitiva da Música.

Embora tenhamos a convicção de que o uso de computadores não possa e não deva substituir o educador musical, muitos professores se manifestam, a priori, contrários à adoção deste tipo de tecnologia. Sabemos que o uso da informática na educação ainda pode gerar algumas controvérsias. Isso ocorre menos no contexto das Ciências Exatas, pois a solução de problemas matemáticos e lógicos já é realizada há mais de quarenta anos com o auxílio do computador. Entretanto essa resistência ainda é compreensível quando aparece nas Ciências Humanas e nas Artes, como é o caso da Música.

Acreditamos que uma maior divulgação dos fundamentos e das ferramentas computacionais disponíveis para músicos e professores de música pode auxiliá-los a expandir seus conhecimentos, vencer seus receios e preconceitos e torná-los interessados em partilhar experiências sobre a aplicação de tecnologia ao ensino da música. Cremos que essa mudança de atitude resulta de um acesso maior a informações e de uma constatação, na prática, dos benefícios do uso complementar de sistemas informatizados no processo de ensino/aprendizagem.

Nossa utilização de computadores na educação, em particular na Educação Musical tem duas premissas:

Os programas de computador devem ser vistos como mais uma possibilidade para auxiliar o professor na prática do ensino, não se pretende substituir o professor;

O professor decide as formas mais adequadas de utilização de ferramentas computacionais para enriquecer o ambiente de aprendizagem

Podemos observar três níveis de utilização de software na educação musical:

1. O uso de software musical em geral (editores de partituras, seqüenciadores, etc.), como ferramenta educativa, embora não tenha sido criado especificamente com este objetivo em mente;

2. O uso de software especificamente educativo-musical (treinamento auditivo, tutores teórico-musicais, etc.), criado especificamente para educação musical; e

3. A programação sônica, que permite aos músicos a criação de seu próprio software, adaptado a uma estratégia de ensino particular ou para situações de ensino específicas que envolvam programação de computadores (ensino de composição eletroacústica, por exemplo). 
Embora o professor de música possa utilizar qualquer software de uso geral (inclusive editores de texto, editores de imagens, etc.) como ferramenta educativa, neste trabalho nos concentramos no software musical, utilizado mais freqüentemente pelos músicos. Nesta seção abordaremos apenas o primeiro e o segundo dos níveis citados acima. Uma discussão mais aprofundada do nível 3 pode ser encontrada em (Fritsch, 2002) ou em (Miranda, 2001).

A seção 3 fornece uma visão panorâmica dos diferentes tipos de software musical (e suas principais características) classificados de acordo com suas funcionalidades e ainda algumas sugestões de utilização para o ensino de música.

Apesar dos músicos reconhecerem a importância da sua formação através de uma sólida educação musical, surpreendentemente muito pouco software é desenvolvido especialmente para isto. De fato, poucos pesquisadores de Informática na Educação abordam questões de Educação Musical e assim a seção 4 resume os trabalhos de pesquisa de nosso grupo visando especificamente o desenvolvimento de software educativo-musical.

\section{Software musical na aula de música, como escolher?}

Nosso objetivo com esta seção é auxiliar o professor de música a decidir livremente se usar, onde usar e como usar software musical em suas aulas.

\subsection{Software para acompanhamento}

É o tipo de software que produz um auto-acompanhamento e ritmos em tempo-real, semelhante aos teclados de acompanhamento automático, quando são executadas notas em um instrumento MIDI (MIDI, 2003), permitindo ao usuário realizar composições, arranjos e auto-acompanhamento. Esta categoria de software pode ser utilizada em aulas de técnicas interpretativas e harmonia em que o estudante de música elabora um acompanhamento para executar exercícios de improvisação e arranjo musical.

\subsection{Software para edição de partituras}

Serve para editar e imprimir partituras, permitindo a inclusão de notas tanto usando o mouse como diretamente de uma execução em instrumento MIDI. A gravação e execução em tempo real da música por meio de instrumento MIDI são também características úteis. Permite, ainda, importar arquivos no formato MIDI gerado por outros programas. Geralmente possuem bastante flexibilidade permitindo escolher tipos de pautas (normal, tablatura, ritmo), símbolos musicais, múltiplas vozes por pauta, etc., além de oferecer recursos para edição da letra da música. Há também facilidades para se acessar e extrair partes da partitura e a impressão, em geral, pode ser dimensionada e configurada pelo usuário. O recurso de edição de partitura auxiliada por computador pode ser utilizado para exercícios de instrumentação e orquestração de peças musicais em que o estudante compõe para os vários instrumentos de um conjunto ou de uma orquestra e, posteriormente, realiza a audição da partitura como uma amostra. Essa amostra servirá para o estudante realizar uma avaliação de seu próprio trabalho antes de submetê-lo ao conjunto ou à orquestra.

\subsection{Software para gravação de áudio}

Permite gravar múltiplas e simultâneas trilhas de áudio digitalizado. Estes programas facilitam as atividades de composição já que permitem procedimentos como o overdub, isto é, a gravação de um instrumento como base em uma trilha (canal) e em seguida os demais em outras trilhas, ouvindo o instrumento base já gravado. Com os dados sonoros V. 2 № 1, Março, 2004 
na memória do computador temos inúmeras possibilidades de manipular o som digitalmente para obter resultados desejados, como o processamento (edição) de algumas características do som, equalização, afinação, compressão de tempo, etc. Muito utilizado no ensino de música eletroacústica em que os alunos utilizam um sistema não tradicional de composição. O estudante pode utilizar o computador como um estúdio completo de gravação para registrar seus exercícios e composições eletroacústicas, aprimorar técnicas de gravação e processamento do som.

\subsection{Software para instrução musical}

Em geral são programas utilizados para o estudo de teoria e percepção ou, então, o auxílio ao aprendizado de um instrumento musical. Ao contrário de outras categorias de software musical, como seqüenciadores e gravadores digitais, os programas de instrução são desenvolvidos exclusivamente para o músico que deseja utilizar o computador para aprender sobre determinada área da música. Nesta categoria de software também estão incluídos os CD-ROMs multimídia e Websites sobre história da música e biografia de compositores.

\subsection{Software para seqüenciamento musical}

Permite gravação, execução e edição de músicas tipicamente no formato MIDI. A música instrumental é gravada via MIDI, usando um teclado ou outro tipo de instrumento controlador MIDI, e armazenada pelo software, podendo, então, ser editada. Como não são sons que estão armazenados, e sim, as informações de execução das notas, é possível escolher diferentes instrumentos para tocar a mesma música. A música criada no sequienciador pode ser exportada para outros programas MIDI (por exemplo o editor de partituras) usando o formato padrão Standard MIDI File. Também é possível importar músicas de outro software para editá-las.

Podemos, em alguns desses programas, gravar trilhas de áudio digital junto com a música MIDI e, assim, operar como o gravador de áudio. Dessa forma, eles integram as duas tarefas (sequienciamento MIDI e gravação de áudio) e tornam a operação mais fácil para o usuário.

Possibilita ao aluno desenvolver exercícios de composição, harmonia e notação musical através da partitura ou da função de piano roll. Através de recursos como edição, quantização, transposição, alteração de andamento e de programa (preset), é possível corrigir erros de execução, aprimorar a instrumentação utilizada, modificar tonalidade e visualizar os resultados graficamente. Este processo permite ao estudante um maior controle sobre suas soluções aos problemas de instrumentação, arranjo e composição.

\subsection{Software para síntese sonora}

Esses programas geram sons (timbres) a partir de amostras sonoras armazenadas ou por algum processo de síntese digital. Alguns programas sintetizadores podem tocar os sons em tempo-real, a partir de comandos de notas MIDI executados por um seqüenciador ou por uma pessoa tocando um instrumento MIDI. Atualmente, os ambientes para síntese (sintetizadores virtuais) caracterizam-se pela facilidade de uso da sua interface gráfica, onde os controles dos parâmetros de síntese são exibidos como botões e sliders, facilitando a interação e simulando o funcionamento dos sintetizadores reais.

Dentro dessa categoria existem os editores de timbres. Através da interface MIDI que conecta o computador ao teclado sintetizador, o usuário pode carregar os 
dados da memória deste para a memória do computador, editá-los, armazená-los, realizar cópias de segurança e enviá-los de volta para a memória do instrumento.

$\mathrm{O}$ aluno tem a possibilidade de criar seus próprios instrumentos, desenvolvendo, através dessa atividade, sua habilidade de pesquisar novos sons. Ao criar um catálogo de novos sons, o aluno poderá organizá-lo com base em técnicas de composição e princípios estéticos.

\subsection{Resumo}

A Tabela 1 resume, por categoria ,alguns produtos existentes no mercado. A coluna Recursos desejáveis para uma boa utilização do software sugere as características e funcionalidades mais relevantes para uso do software de acordo com o tipo em que ele está classificado. A coluna Requisitos mínimos para uso indica a necessidade de equipamentos, periféricos e outros dispositivos, alertando o professor no sentido de que outros recursos extras são necessários além do software. A coluna Exemplos de software apresenta alguns produtos que estão disponíveis no mercado e que podem ser usados como uma boa opção de ferramenta no ensino da música.

\begin{tabular}{|c|c|c|c|}
\hline Categoria & Recursos desejáveis para utilização do software & $\begin{array}{l}\text { Requisitos mínimos para } \\
\text { uso }\end{array}$ & Exemplos \\
\hline Acompanhamento & $\begin{array}{l}\text { Biblioteca de estilos, controle do arranjo, editor de } \\
\text { estilos, gravação da melodia, harmonização da melodia, } \\
\text { controles de expressividade, impressão da partitura, } \\
\text { edição e impressão da letra da música, configuração de } \\
\text { sintetizador e suporte a MIDI File. }\end{array}$ & $\begin{array}{l}\text { Interface MIDI, teclado ou } \\
\text { controlador MIDI e } \\
\text { impressora. }\end{array}$ & $\begin{array}{l}\text { Arranger's tool, Band- } \\
\text { in-a-box, CAMPS, } \\
\text { Jammin'keys, Visual } \\
\text { Arranger, WinChime. }\end{array}$ \\
\hline Edição de partitura & $\begin{array}{l}\text { Tipos de claves, múltiplas vozes, letra da música e cifra, } \\
\text { ferramentas de edição, editor de símbolos, } \\
\text { gravação/execução via MIDI, quantização, seleção de } \\
\text { bancos, listas de instrumentos, múltiplas portas MIDI, } \\
\text { suporte a arquivos Standard MIDI File. }\end{array}$ & $\begin{array}{l}\text { Interface MIDI, instrumento } \\
\text { controlador } \\
\text { impressora. }\end{array}$ & $\begin{array}{l}\text { Sibelius, Encore, } \\
\text { Finale. }\end{array}$ \\
\hline Gravação de áudio & $\begin{array}{l}\text { Múltiplas entradas e saídas de áudio, suporte a vários } \\
\text { arquivos de áudio, gravação multipista, controle de } \\
\text { volume e pan, ferramentas de edição, processamento de } \\
\text { sinal, sincronização externa, recursos de backup, } \\
\text { instrumentos virtuais. }\end{array}$ & $\begin{array}{l}\text { Placa de áudio, espaço em } \\
\text { disco, equipamentos para } \\
\text { gravação e audição, } \\
\text { velocidade de processamento } \\
\text { e dispositivo de backup. }\end{array}$ & $\begin{array}{l}\text { Pro Tools, Sonar, } \\
\text { Logic Audio } \\
\text { Platinum, SAW } \\
\text { Studio, SoundForge. }\end{array}$ \\
\hline Instrução & $\begin{array}{c}\text { Diversidade de exercícios, tabela de resultados, suporte a } \\
\text { MIDI, níveis de dificuldade. }\end{array}$ & $\begin{array}{l}\text { Interface MIDI, instrumento } \\
\text { MIDI, microfone, placa de } \\
\text { áudio. }\end{array}$ & $\begin{array}{l}\text { Multimedia Elements } \\
\text { of Music, Musique, } \\
\text { Keyboard Intervals, } \\
\text { Auralia, Ear Training, } \\
\text { Listen, Keyboard } \\
\text { Skills, Music Lessons. }\end{array}$ \\
\hline Seqüenciamento & $\begin{array}{l}\text { Configuração do modo de gravação MIDI em replace, } \\
\text { loop, overdub, punch-in-out, ferramentas de edição, } \\
\text { quantização, suporte a seleção de bancos de som, listas de } \\
\text { instrumentos, múltiplas portas MIDI, edição gráfica, } \\
\text { mixer, visualização da partitura, sincronismo externo, } \\
\text { suporte a SysEx, trilhas de áudio, instrumentos virtuais. }\end{array}$ & $\begin{array}{l}\text { Interface MIDI, controlador } \\
\text { MIDI, dispositivo SMTPE, } \\
\text { placa de áudio, espaço e } \\
\text { velocidade no disco rígido, } \\
\text { equipamentos de áudio, } \\
\text { computador rápido, }\end{array}$ & $\begin{array}{l}\text { Cakewalk, Cubase, } \\
\text { Logic Audio, Vision. }\end{array}$ \\
\hline Síntese & $\begin{array}{c}\text { Polifonia, multitimbralidade, mais de uma técnica de } \\
\text { síntese sonora além da subtrativa, possibilidade de } \\
\text { expansão, compatibilidade MIDI, no mínimo três tipos de } \\
\text { filtro (BPF, HPF, LPF), modificadores como LFO, S/H, } \\
\text { ADSR, Envelope Follower, Vocoder. }\end{array}$ & $\begin{array}{l}\text { Placa de áudio, velocidade de } \\
\text { processamento, espaço em } \\
\text { disco, interface MIDI. }\end{array}$ & $\begin{array}{c}\text { VAZ, Virtual } \\
\text { SoundCanvas, } \\
\text { Reaktor, Csound, } \\
\text { MaxMSP, editores } \\
\text { como o Clavia Nord } \\
\text { Modular e plug-ins } \\
\text { como o PPGWave. }\end{array}$ \\
\hline
\end{tabular}

Tabela 1- Categorias, Características e exemplos de software musical 


\section{Desenvolvendo Software Educativo-Musical}

Nesta seção, apresentaremos um panorama de alguns dos principais trabalhos desenvolvidos especificamente para Educação Musical e utilizados em situações reais de aplicação e avaliação experimentadas no Laboratório de Computação e Música (LC\&M, 2003) e Centro de Música Eletrônica (CME, 2003) da Universidade Federal do Rio Grande do Sul (UFRGS). Uma analise das questões sobre a interdisciplinaridade entre educação musical e informática, é preliminarmente abordada em (Krüger et al. 1999).

O STR (Sistema de Treinamento Rítmico (Fritsch et al. 1998)) é um dos resultados dessa experiência conjunta que demonstrou a importância do trabalho em equipe multidisciplinar, onde o conhecimento teórico e prático dos componentes resultou em um programa fundamentado em conceitos atuais em ambas as áreas. Este sistema, ver exemplo na Figura 1, se destina ao estudo da teoria do ritmo musical requerendo soluções computacionais que tratam o tempo de eventos musicais, como a duração das notas musicais e o tempo exato entre suas execuções.

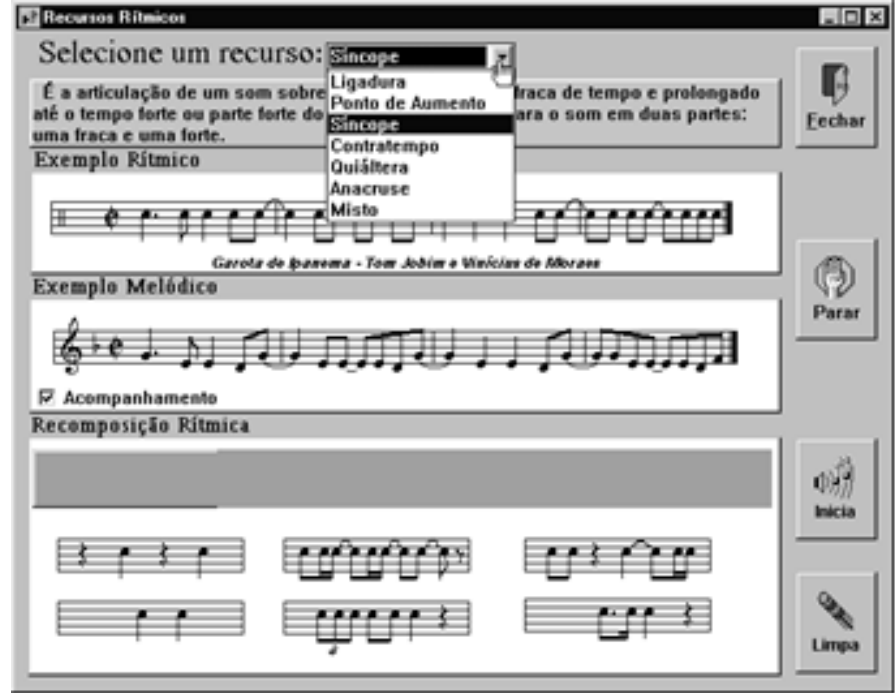

Figura 1 - Tela de composição rítmica do STR

O STI (Sistema para Treinamento de Intervalos (Flores, 2000)), Figura 2, é uma aplicação multimídia para auxiliar o aprendizado da teoria dos intervalos musicais melódicos (tópico da teoria musical) a estudantes de música. Mais do que conteúdo teórico, esse sistema apresenta exercícios práticos, como ditado intervalar e assimilação de intervalos, que fazem parte do currículo regular de música, além de fornecer o acompanhamento do desempenho do aluno. Seu desenvolvimento segue uma proposta centrada no usuário, adaptada a projetos de software educacional (Winckler et al., 2000), onde num "ciclo de prototipação" sucessivos protótipos são criados e avaliados, evoluindo até o produto final. 


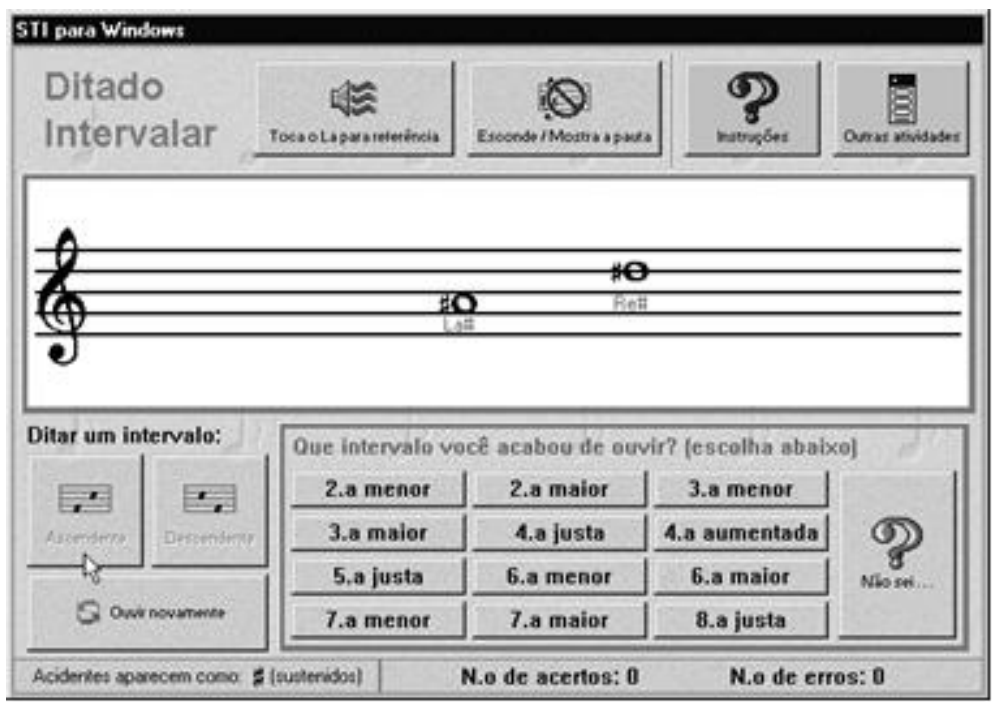

Figura 2 - Tela de ditado intervalar do STI

O SETMUS (Sistema Especialista para Teoria Musical), Figura 3, é uma aplicação multimídia criada com o objetivo de auxiliar o aprendizado de escalas e arpejos. O software dispõe de uma "calculadora musical" na qual o estudante pode acessar rapidamente escalas nos modos maiores e menores. O conteúdo musical do software destina-se a alunos iniciantes na música que desejam exercitar o conhecimento na área de teoria e percepção musical. O sistema foi desenvolvido inicialmente em Hypercard para Macinstosh (Fritsch \& Viccari, 1995) e posteriormente reprogramado em ToolBook para ambiente Windows (Zucco, 1997).

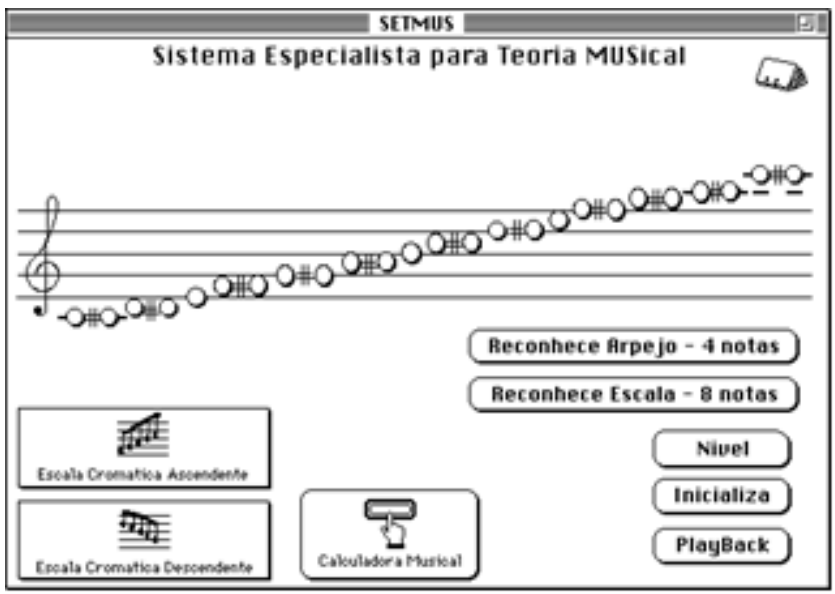

Figura 3 - Tela do sistema SETMUS

O MEPSOM (Método de Ensino de Programação Sônica para Músicos (Fritsch, 2002)) consiste numa associação de ferramentas computacionais que disponibiliza um conjunto de atividades para programação de software musical composto de exemplos e exercícios. O método foi idealizado para ser uma ferramenta de auxílio ao professor em cursos de Computação Musical, disponibilizando recursos didáticos para o ensino de programação nas áreas de composição e educação musical. Implementado sob a forma de programas de computador o método está sendo utilizado em cursos de Pósgraduação, Graduação e Extensão em música na UFRGS. Ver exemplo na Figura 4. 


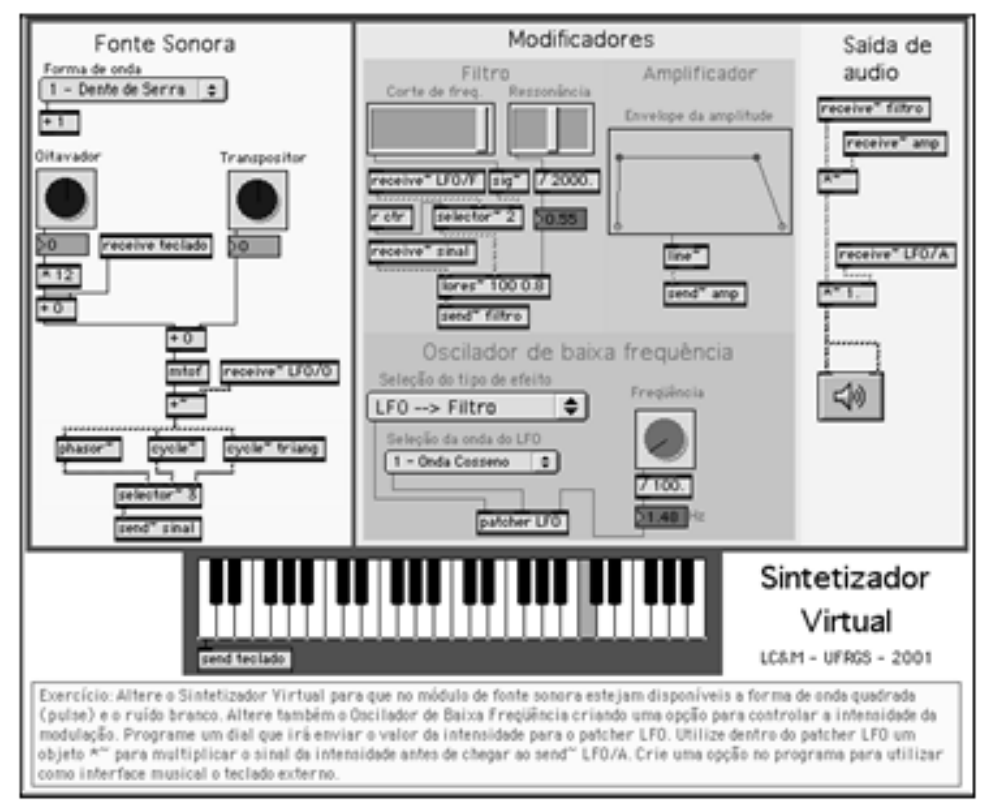

Figura 4 - Tela do sintetizador virtual do MEPSOM com exercícios

Em termos metodológicos julgamos importante destacar os resultados obtidos em dois experimentos de avaliação realizados com versões sucessivas do STI, envolvendo: a validação com usuários, avaliação heurística com especialistas em interfaces e com especialistas no domínio da aplicação, assim como avaliação de aspectos pedagógicos segundo um roteiro específico para avaliação de programas para educação musical. Estes experimentos propiciaram uma situação incomum na maioria dos projetos - a possibilidade de comparar resultados de duas avaliações - e permitiram identificar diferenças e similaridades que confirmam aspectos interessantes sobre $o$ processo de avaliação de software educacional, que podem ser consultados em (Valiati et al., 2002).

Outros trabalhos do grupo encontram-se em desenvolvimento e visam explorar as potencialidades do uso da Internet e suas características. Entre eles destacam-se o projeto do Portal da Música Computacional e Eletrônica do Rio Grande do Sul (Miletto et al., 2002), acessível no endereço Web http://www.musicaeletronica.ufrgs.br/projeto/projeto.html e cujo intuito é ser o foco para a consolidação de uma comunidade virtual com a inclusão de pessoas interessadas em trocar experiências sobre a aplicação de tecnologia à música. Neste contexto também se destaca o Ambiente para Composição Musical Coletiva na Web (Miletto, 2003), cujo objetivo é criar um suporte tecnológico na Web ao processo coletivo de criação de peças musicais em grupo, onde cada membro do grupo pode não só criar/propor/modificar seus próprios trechos musicais, mas também ter acesso, escutar e propor modificações a trechos musicais dos outros membros do grupo. Esperamos que este ambiente disponibilizado na WWW possa despertar a curiosidade de pessoas com diferentes formações (principalmente pessoas com pouco conhecimento formal em música) e de diferentes localidades, aproximando-as com o objetivo de criar uma comunidade virtual de músicos em potencial.

Apoiado nestas mesmas premissas de inclusão social através da inclusão digital, desenvolvemos o Sistema Multiagente para Simulação de Performance Rítmica no Violão (Costalonga et al., 2003), que usa em uma notação musical mais popular para 
simplificar o processo de aprendizagem do iniciante em música. Com esta proposta, a tecnologia se aproxima da comunidade de músicos "não acadêmicos" despertando o interesse dos mesmos pela computação (inclusão digital) e propiciando um estudo mais aprofundado da música.

\section{Discussão e Comentários Finais}

Pesquisas têm sido realizadas no sentido de aplicar recursos tecnológicos à área musical, porém apenas um pequeno número destas destina-se à educação, podendo ser utilizadas pelo professor de música no seu dia a dia. Este trabalho procurou apresentar algumas considerações sobre a educação musical utilizando o computador, bem como relatar as atividades que estão sendo desenvolvidas no LC\&M e CME da UFRGS nesse sentido.

Nossa experiência na área de Educação Musical Auxiliada por Computador é fruto de investigação, desenvolvimento e aplicação de muitos conceitos, modelos e ferramentas. Neste processo contínuo de pesquisa, temos aprendido muitas lições importantes e nesta seção podemos destacar algumas delas.

Educação Musical Auxiliada por Computador é um domínio eminentemente multidisciplinar e nossa intenção é formar equipes efetivamente multidisciplinares, envolvendo pessoas não só oriundas de áreas como Música e Informática mas também de subáreas mais específicas como Computação Musical, Educação Musical, Informática na Educação, Interação Homem-Computador e Inteligência Artificial. Apesar de parecer um objetivo óbvio, sua concretização não o é. Qualquer pesquisador que tenha trabalhado em grupos multidisciplinares, sabe das peculiaridades de comunicação e organização que isto envolve. Nosso grupo é formado por membros oriundos da Informática, da Informática na Educação e da Música, com todo o enriquecimento e todas as dificuldades que isto traz e pretendemos continuar investindo nesta "miscigenação cultural" pois tem sido muito proveitosa. Além disto, uma área que congrega tantos temas e disciplinas motiva muitas pesquisas subjacentes e secundárias que são por sí só instigantes.

Como nossa pesquisa envolve integração de muitos conceitos e teorias além da definição, implementação e aplicação de muitas idéias, modelos e ferramentas, nosso grupo tem uma filosofia de trabalho pragmática: nosso trabalho teórico é sempre acompanhado de experimentação e validação com usuários reais em contextos reais em muitas situações professores e alunos de música em cursos ou disciplinas reais. Isto consolida os resultados de nossas pesquisas e permite uma contínua reflexão sobre nosso trabalho e revisão constante de nossas metas.

A aplicação prática dos programas desenvolvidos até então, na área da música, já foi realizada em várias oportunidades. Sistemas como o STI e o SETMUS foram utilizados no laboratório do Projeto Prelúdio da UFRGS. Um projeto piloto possibilitou a utilização do STR na Escola Técnica da UFRGS para auxiliar o aprendizado de ritmo aos alunos de segundo grau. O MEPSOM está sendo aplicado como método de ensino de programação para estudantes do curso de graduação em composição da UFRGS desde o primeiro semestre de 2000. Os alunos de composição cursam disciplinas de fundamentos na área de Música \& Tecnologia e, posteriormente, utilizam o computador como ferramenta para desenvolver seus próprios algoritmos para criação de música. $\mathrm{O}$ material musical obtido a partir do resultado dos programas é registrado, processado e organizado para ser utilizado em composições.

Finalmente, embora tenhamos constatado que é significativo o aumento do 
conhecimento sobre música propiciado através da Educação Musical Auxiliada por Computador, pretendemos que nossa pesquisa propicie conseqüências mais importantes como a inclusão social através de inclusão digital e que a educação musical auxiliada por computador funcione como um elemento catalisador para isto.

\section{Referências Bibliográficas}

COSTAlONGA, L. L.; MiletTo, E. M.; FlORES, L. V.; AlVARES, L. O. C.; VICARI, R. M. Um Sistema Multiagente para Simulação de Performance Rítmica no Violão . Anais do IX Simpósio Brasileiro de Computação Musical, agosto de 2003, em Campinas, SP. (to appear)

FLORES, L. V. STI - Sistema para Treinamento de Intervalos para Plataforma Windows 95/98. Projeto de Diplomação (Bacharelado em Ciência da Computação) - Instituto de Informática, Universidade Federal do Rio Grande do Sul, Porto Alegre. 2000.

FlOres, L. V.; VICARI, R. M.; PIMENTA, M. S. Some Heuristics for the Development of Music Education Software: First Steps Towards a Methodology. In: Brazilian Symposium on Computer Music, 8., 2001, Fortaleza. CD-ROM dos Anais do XXI Congresso da Sociedade Brasileira de Computação. Niterói: Instituto Doris Ferraz de Aragon, 2001.

FLORES, L. V. Conceitos e Tecnologias para Educação Musical Baseada na Web. Dissertação (Mestrado em Ciência da Computação). Porto Alegre: PPGC / UFRGS, 2002.

FRITSCH, E. F.; Viccari, R. M. SETMUS: Uma Ferramenta Computacional para o Ensino da Música . In: Simpósio Brasileiro de Computação e Música, 2., 1995, Canela - RS. Anais... Porto Alegre: Instituto de Informática / UFRGS, 1995. p.267-273.

FRITSCH, E. F. et al. Desenvolvimento de Software Educacional para a Música: STR - Sistema de Treinamento Rítmico. In: Simpósio Brasileiro de Computação e Música, 5., 1998, Belo Horizonte. Anais do XVIII Congresso Nacional da Sociedade Brasileira de Computação, v.3. Belo Horizonte: Escola de Música / UFMG, 1998. p.209-218.

FRITSCH, E. F. MEPSOM: método de ensino de programação sônica para músicos . Tese (Doutorado em Ciência da Computação) - Instituto de Informática, Universidade Federal do Rio Grande do Sul, Porto Alegre, 2002.

GAMEZ, L. TICESE - Técnica de inspeção de conformidades ergonômicas em software educacional . 1998. Dissertação (Mestrado em Computação) - Universidade do Minho, Guimarães, Portugal. cap.4, p.1-2. Disponível em: <www.labiutil.inf.ufsc.br/estilo/Ticese.htm>. Acesso em: jun. 2003.

KON, F.; IAZZETTA, F. Internet Music: Dream or (Virtual) Reality? In: Simpósio Brasileiro de Computação e Música, 5., 1998, Belo Horizonte. Anais do XVIII Congresso Nacional da Sociedade Brasileira de Computação, v.3. Belo Horizonte: Escola de Música / UFMG, 1998. p.69-81.

KRÜGER, S. E.; FRITSCH, E. F.; FLORES, L. V.; GRANDI, R. H.; SANTOS, T. R.; HENTSCHKE, L.; VICCARI, R. M. Developing a Software for Music Education: An Interdisciplinary Project . In: Simpósio Brasileiro de Computação e Música, 6., 1999, Rio de Janeiro. Anais do XIX Congresso Nacional da Sociedade Brasileira de Computação, v.3. Rio de Janeiro: EntreLugar, 1999. p.251-264.

MIDI. Associação de Fabricantes MIDI . Disponível em: <www.midi.org>. Acesso em: jun. 2003.

MILETTO, E. M.; FRITSCH, E. F.; FLORES, L. V.; LOPES, N.; COSTALONGA, L. L.; PIMENTA, M. S. Rumo ao portal de música computacional e eletrônica . In: Fórum do Centro de Linguagem Musical, 5., 2002, São Paulo. Anais. 2002. v.1. p.104-107.

miletto, E. M.; PIMEnTA, M. S. Rumo a um Ambiente para Composição Musical Coletiva Baseado na Web . Anais do IX Simpósio Brasileiro de Computação Musical, agosto de 2003, em Campinas, SP. (to appear)

HENTSCHKE, Liane. Um Estudo Longitudinal Aplicando a Teoria Espiral de Desenvolvimento Musical de Swanwick com Crianças Brasileiras da Faixa Etária de 6 a 10 Anos de Idade : Pólo Porto Alegre - 1994. In: Música: Pesquisa e Conhecimento 2. Porto Alegre: CPG em Música - Mestrado e Doutorado / UFRGS - NEA, 1996. p.9-34.

SWANWICK, K. A Basis for Music Education . London: Routledge, 1979. 
SWANWICK, K. Music, Mind and Education. London : Routledge, 1988.

MIRANDA, E. R. Composing Music with Computers. Oxford: Focal Press,

2001

VAliATI, E. R. A., FLORES, L. V., MILETTO, E. M., PIMENTA, M. S. Avaliação de interfaces em software educacional: comparando experiências em dois protótipos sucessivos. In: XXVIII Conferencia Lationoamericana de Informática, Anais do InfoUYCLEI 2002. Montevideo: CLEI, 2002.

WINCKLER, M. A. A.; NEMETZ, F.; LIMA, J. V. Interação entre Aprendiz e Computador: Métodos para Desenvolvimento e Avaliação de Interfaces. In: Tarouco, L. M. R. (Ed.) Tecnologia Digital na Educação . Porto Alegre: Pós-Graduação em Informática na Educação, UFRGS. p.7-33. 2000.

ZUCCO, L. A. Reprogramação do SETMUS para plataforma PC. 1997. Trabalho de Conclusão de Curso (Graduação em Sistemas de Informação) - Universidade Luterana do Brasil, Canoas. 